\title{
The effect of restrictive policy instruments on Belgian fishing fleet dynamics
}

\author{
Hendrik Stouten ${ }^{1, a}$, Aimé Heene ${ }^{2}$, Xavier Gellynck ${ }^{3}$ and Hans Polet ${ }^{4}$ \\ ${ }^{1}$ Institute for Agriculture and Fisheries Research (ILVO)/Faculty of Economics and Business Administration, Ghent University Ankerstraat 1, \\ 8400 Ostend, Belgium \\ 2 Department Management and Organization, Faculty of Economics and Business Administration, Ghent University Tweekerkentstraat 2, \\ 9000 Ghent, Belgium \\ 3 Department of Agricultural Economics, Faculty of Bio-Science Engineering, Ghent University Coupure Links 653, 9000 Ghent, Belgium \\ ${ }^{4}$ Institute for Agriculture and Fisheries Research (ILVO) Ankerstraat 1, 8400 Ostend, Belgium
}

\begin{abstract}
Even with the rapid changes in the level of complexity and the uncertainty of the environment in which Belgian sea fisheries operate, fisheries management in Belgium is still mainly based on restrictive policy instruments founded in the biological approach of fisheries management science. Since they will continue to play an important role, this paper evaluated changes in three restrictive policy instruments and their effect on future fleet performance and dynamics, i.e. maximum fishing days, total quota-restrictions and licences. These effects are tested through scenarios in a microeconomic simulation model, including sensitivity analysis. This study opts for a dynamic simulation model based on a microeconomic approach of fleet dynamics using system dynamics as a modelling technique (operational base: Vensim®DSS). The results indicated that changes in maximum fishing days and total quota resulted in higher fluctuations in fleet performance and dynamics compared to changes in licences. Furthermore, changes in maximum fishing days and total quota had a direct impact on fleet performance, though not always as expected, whereas licences only affected fleet performance indirectly since they only limit the entry of new vessels to the fleet and they can block the growth of successful sub fleets. The outcomes of this study are translated into practical recommendations for improving fisheries management. Firstly, policy makers need to be more aware of misperceptions of feedback. Secondly, the results proved that altering only one type of restrictive policy instrument at a time often fails to meet desired outcomes. Therefore, policy makers need to find a balance in combining policy instruments. Finally, this paper opens the discussion on the future value of restrictive policy instruments in the rapidly changing, complex and uncertain fisheries environment. It suggests rethinking their use from "preserving a status quo and social peace" toward a driving factor in "stimulating fleet dynamics".
\end{abstract}

Key words: Fisheries management / Restrictive policy instruments / Sensitivity simulation / System dynamics / Fleet performance / Fleet dynamics

\section{Introduction}

Even with the rapid changes in the level of complexity (Healey and Hennessey 1998; Lane and Stephenson 1999) and the uncertainty (Charles 1998; Cochrane 1999) of the environment in which Belgian sea fisheries operate, fisheries management in Belgium is still mainly based on restrictive policy instruments (often imposed by the European Union) founded in the biological approach of fisheries management science. Since they will continue to play an important role, this study

\footnotetext{
a Corresponding author:

Hendrik.Stouten@ilvo.vlaanderen.be
}

examines their potential future effects on Belgian fleet performance and dynamics. Three restrictive policy instruments are under research: (i) total quota restrictions, (ii) the effort restriction of maximum days at sea, and (iii) the limited entry program of fishing licenses.

Their future effects are analysed through scenarios in a dynamic simulation model based on a microeconomic approach of fleet dynamics and sensitivity analysis. The Belgian sub fleets are the key agents in the model and their gross operating profit and fleet size are the key variables of interest. As a result, the model takes the perspective of sub fleets. The model consists of four homogeneous sub fleets, three fishing grounds, one theoretical average species and three restrictive 
Table 1. Key figures of the Belgian fleet illustrating its evolution between 1950 and 2005 .

\begin{tabular}{cccc}
\hline & $\begin{array}{c}\text { Number of } \\
\text { vessels }\end{array}$ & $\begin{array}{c}\text { Average } \\
\text { GT per } \\
\text { vessel }\end{array}$ & $\begin{array}{c}\text { Average } \\
\text { kW per } \\
\text { vessel }\end{array}$ \\
\hline $\mathbf{1 9 5 0}$ & 457 & 58 & 97 \\
$\mathbf{1 9 6 0}$ & 415 & 70 & 134 \\
$\mathbf{1 9 7 0}$ & 332 & 94 & 223 \\
$\mathbf{1 9 8 0}$ & 208 & 102 & 302 \\
$\mathbf{1 9 9 0}$ & 201 & 127 & 384 \\
$\mathbf{1 9 9 5}$ & 155 & 149 & 426 \\
$\mathbf{2 0 0 0}$ & 131 & 182 & 500 \\
$\mathbf{2 0 0 1}$ & 132 & 185 & 511 \\
$\mathbf{2 0 0 2}$ & 129 & 185 & 519 \\
$\mathbf{2 0 0 3}$ & 125 & 189 & 532 \\
$\mathbf{2 0 0 4}$ & 121 & 188 & 542 \\
$\mathbf{2 0 0 5}$ & 119 & 188 & 545 \\
\hline
\end{tabular}

Data source: Belgian Sea Fisheries Service.

policy instruments. The value of this research is threefold. First, it makes policy makers aware of potential future effects restrictive policy instruments can have on fleet performance and dynamics. Second, it gives practical suggestions for the future use of these restrictive policy instruments and for improving fisheries management. Finally, it starts the discussion of the future role restrictive policy instruments can have in managing fleet performance and dynamics.

The paper contains four sections. Section one on materials and methods describes the simulation model consisting of the main interaction between the Belgian fleet and the restrictive policy instruments. Section two contains the results which clearly indicate differences in the impact of restrictive policy instruments on future fleet performance and dynamics. Section three discusses the results, gives practical suggestions for improving fisheries management, and discusses the future role of restrictive policy instruments, and finally, conclusions are drawn.

\section{Materials and methods}

The study uses the Belgian fleet as a case study. This fleet consists of four important sub fleets: (i) the shrimp trawler fleet: beam trawlers targeting shrimps (13\% of the total fleet in 2005), (ii) the fleet of eurocutters: beam trawlers with an engine power between $200 \mathrm{~kW}$ and $221 \mathrm{~kW}$ not targeting shrimps (30\% of the total fleet in 2005), (iii) the large beam trawler fleet: beam trawlers with an engine power higher than $662 \mathrm{~kW}$ not targeting shrimps (44\% of the total fleet in 2005), and (iv) the set netter fleet: vessels using set nets as their main fishing method (3\% of the total fleet in 2005).

The Belgian total fleet declined dramatically between 1950 and 2005 from 457 to 119 vessels, but the average gross tonnage and engine power for an average vessel has multiplied, resulting in a small but quite powerful fleet (Table 1). This behaviour is mainly due to a dragging "profitability crisis" caused by increasing operational costs and decreasing catches. As a result, many vessels have exited the fleet or were reengineered toward more powerful vessels. Nevertheless, gross operating profits remained low (Fig. 1) leading to

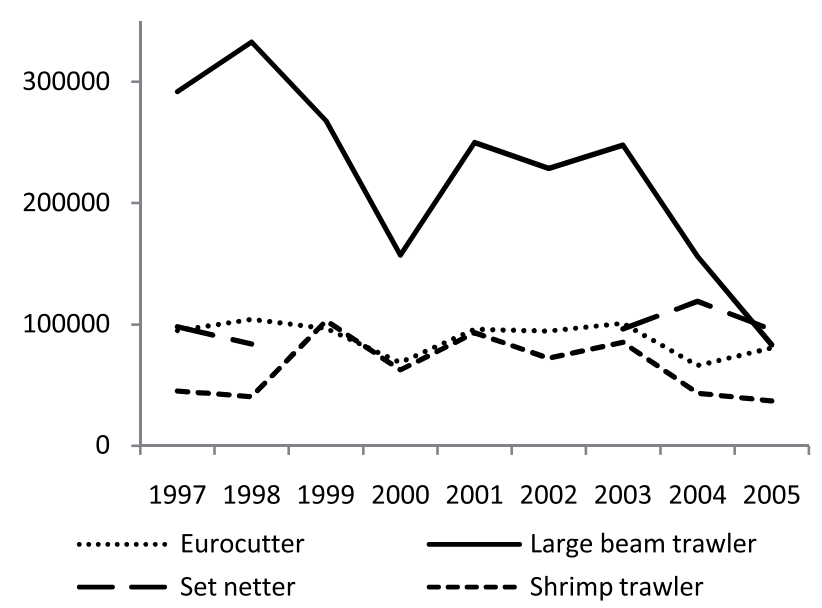

Fig. 1. The evolution of the average gross operating profits for an average Belgian vessel per sub fleet between 1997 and 2005 (in euro).

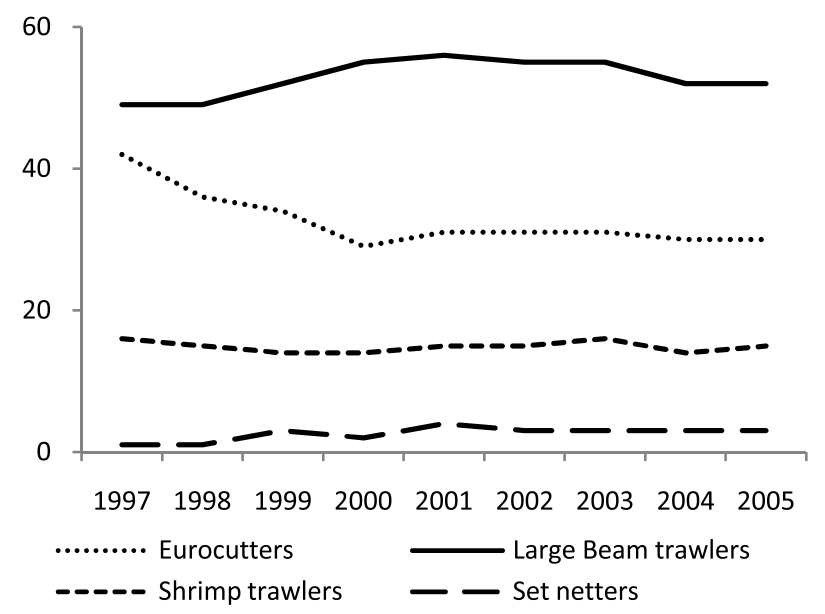

Fig. 2. The evolution of the number of vessels per sub fleet of the Belgian fleet between 1997 and 2005.

Table 2. Gross operating profit for an average vessel of the Belgian fishing sub fleet in 2005 (in euro).

\begin{tabular}{lccccc}
\hline & $N$ & Mean & $\begin{array}{c}\text { Std. } \\
\text { deviation }\end{array}$ & Min & Max \\
\hline Eurocutter & 15 & 80584 & 59813 & -34562 & 186520 \\
$\begin{array}{l}\text { Large beam } \\
\text { trawler }\end{array}$ & 34 & 83087 & 126134 & -144220 & 528738 \\
Set netter & 3 & 95524 & 95168 & 11979 & 199119 \\
Shrimp trawler & 8 & 36711 & 46091 & -15255 & 112558 \\
Other & 9 & 107 & 103813 & -22712 & 274175 \\
& & 525 & & & \\
\hline Total & 69 & 80894 & 102693 & -144220 & 528738 \\
\hline
\end{tabular}

small margins to pay off debts. Table 2 illustrates these low gross operating profits for an average vessel of the sub fleets in 2005 .

However, it also indicates a huge variability between and within sub fleets. Consequently, not every vessel in the Belgian fleet performed insufficiently, which is seen in the dynamics of sub fleets during the last years (Fig. 2). 


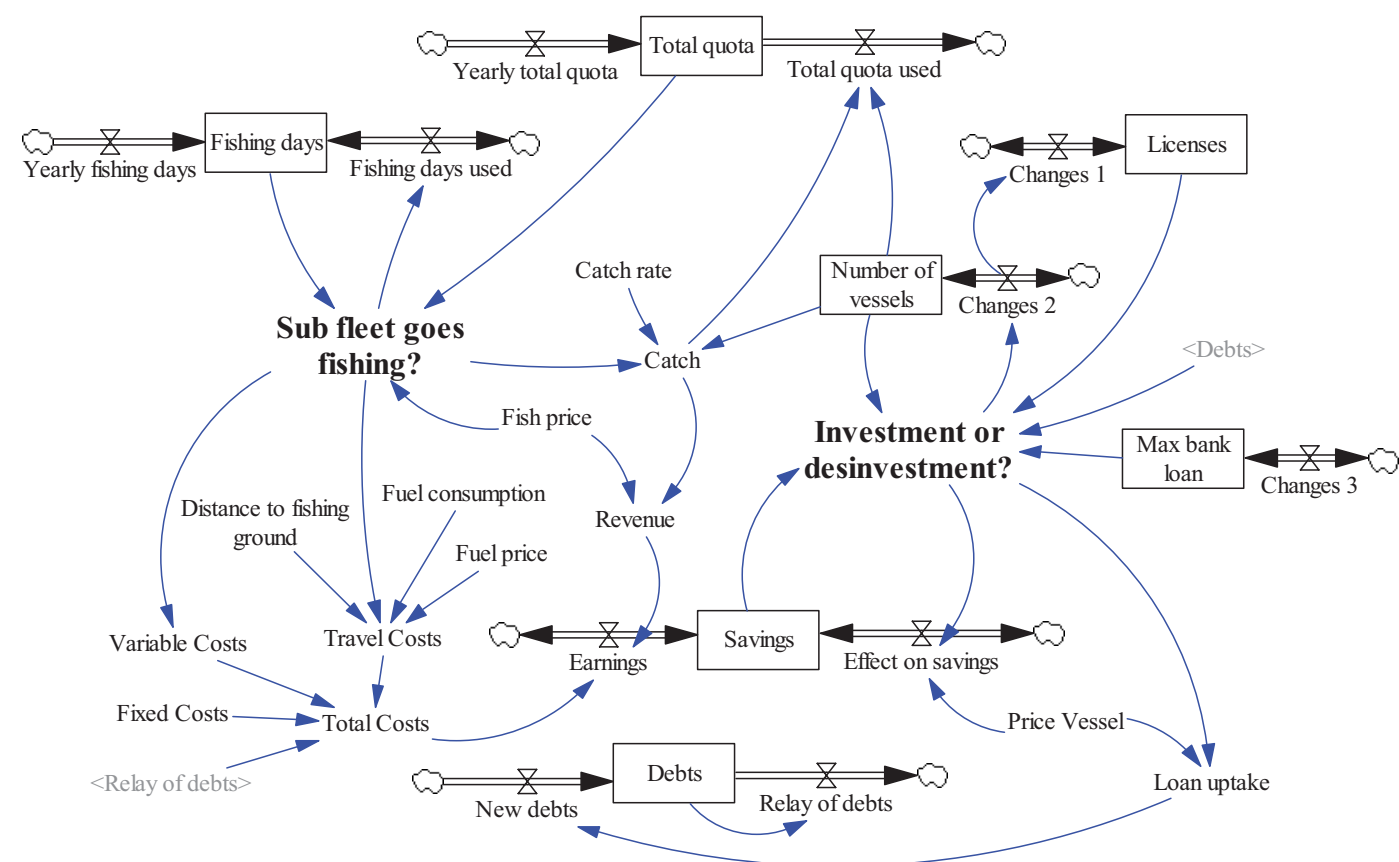

Fig. 3. A simplified representation of the system dynamics simulation model not taking into account the arrays (where: " $\square$ " = stock, "०" = converter, "=>" = in- or outflow, and "bold" = decision algorithms).

To evaluate the future performance and dynamics of the Belgian fleet under restrictive policy instruments, scenarios in a simulation model will be used (time horizon of 18 years with a time step $(\Delta t)$ of a week). This study opts for a dynamic simulation model using system dynamics as a modelling technique (operational base: Vensim®DSS) (Moxnes 1998a, 1998b, 1999, 2003; Dudley 2003, 2003; Stouten et al. 2007). The model is based on insights gained from the literature and from expert group meetings involving fisheries scientists. Additionally, informal contacts with the fishing industry and policy makers have further improved our global understanding of fisheries management. Based on these insights, decisions were made concerning the conceptualisation and scope of the simulation model.

This study applies a microeconomic approach to fleet dynamics in which restrictive policy instruments (i.e. maximum fishing days, total quota size and licences) affect tactical and investment decisions of sub fleets (Mathiesen 2003), resulting in changes in fleet performance and dynamics. Consequently, sub fleets are the key agents in the model and gross operating profit (measured in gross operation profit for an average vessel) and fleet size (measured in number of vessels) of the total fleet are the key variables of interest. As a result, the model takes the perspective of sub fleets and unveils their reinforcing investment loop mainly balanced by the three restrictive policies under research (Fig. 3).

The interactions between these loops cause dynamic complexity (Senge 1990). Gaining insights in how these loops affect the performance and dynamics of sub fleets when restrictive policy instruments are altered is vital in meeting this paper's objective. Therefore, a comprehensible model is chosen above a comprehensive model since detailed complexity (Senge 1990) can blur or block our understanding of dynamic complexity. In line with this principle, four important decisions are made. First, the model does not include a biological component, meaning that stock dynamics are outside the scope of the model. Therefore, this model is no standard bio-economic model. As a result, total quota and catchability are not influenced by biological variables. Second, the agents in the model are "homo economicus". This can be justified since many models concerning fisheries management also use this "homo economicus" principle (Opaluch and Bockstael 1984). Third, profit generated by the sub fleets can only be invested in a new vessel and there is no external investment in the fleet. Finally, the size of the arrays in the model needed to be brief and meaningful (Table 3).

Next, the main economic rules of the model need to be explained (Fig. 3). The model contains two important decision rules: a fishing tactical decision rule and an investment decision rule. The fishing tactical decision rule addresses the sub fleets' choice on where to fish. It sends the sub fleet to the fishing ground with the highest catch per unit of effort if fishing is still possible.

$Z_{s g}(t)$ is defined as a boolean variable that takes the value one on time $t$ if for sub fleet $s$ : (i) fishing is still an option (see further for explanation) on fishing ground $g$ and (ii) fishing ground $g$ is the fishing ground where sub fleet $s$ can catch the most fish per unit of effort. $Z_{s g}(t)$ is zero for all other situations.

Let $P_{\text {fish }}(t)$ be the fish price on time $t$ which is given, $n_{\text {days, }, s}(t)$ the number of fishing days left on time $t$ for sub fleet $s, Q_{g}$ the amount of total quota left for fishing ground $g$ and $c_{s g}(t)$ the catch rate for a given $(s, g)$ on time $t$. The model selects $c_{S G}(t)$ as the maximal catch rate on time $t$ for $(S, G)$.

$$
Z_{s g}(t)=P_{\text {fish }}(t) \text { and } n_{\text {days }, s}(t) \text { and } Q_{G}(t)>0 \text { and } c_{s g}(t)=c_{S G}(t) .
$$


Table 3. The sizes of the arrays in the simulation model.

\begin{tabular}{|c|c|c|}
\hline Simulation model & Reality & Justification \\
\hline $\begin{array}{l}\text { Three restrictive } \\
\text { policy instruments }\end{array}$ & $\begin{array}{l}\text { Five main restrictive policy } \\
\text { instruments }\end{array}$ & $\begin{array}{l}\text { From the five main restrictive policy instruments at hand in Belgium (maximum fishing } \\
\text { days, total quota, licences, closed seasons and closed areas), only three policy } \\
\text { instruments (maximum fishing days, total quota and licences) are the focus of this } \\
\text { paper. Therefore, only these three are taken into account in the model. The effects of } \\
\text { other policy instruments are set to zero. }\end{array}$ \\
\hline Four sub fleets & Four main sub fleets & $\begin{array}{l}\text { This study distinguishes four sub fleets in the Belgian fleet based on vessel length, } \\
\text { fishing method and target species: } \\
\text { 1) the fleet of eurocutters, 2) the large beam trawler fleet, 3) the set netter fleet and } \\
\text { 4) the shrimp trawler fleet. Consequently, our simulation model contains four } \\
\text { homogeneous sub fleets. }\end{array}$ \\
\hline $\begin{array}{l}\text { Six fishing grounds } \\
\text { (aggregated into three } \\
\text { fishing grounds) }\end{array}$ & Ten main fishing grounds & $\begin{array}{l}\text { This simulation model aggregates the six fishing grounds (ICES areas) that contain most } \\
\text { of the Belgian total quota into three fishing grounds: } \\
\text { 1) IVbc, 2) VIIde, and 3) VIIfg. } \\
\text { Therefore, this simulation model underestimates the total amount of Belgian quota. }\end{array}$ \\
\hline $\begin{array}{l}\text { One theoretical } \\
\text { average species }\end{array}$ & $\begin{array}{l}\text { Four important target } \\
\text { species }\end{array}$ & $\begin{array}{l}\text { As a result of choosing comprehensibility above comprehensiveness, the simulation } \\
\text { model runs with one theoretical average species. }\end{array}$ \\
\hline
\end{tabular}

In equation (1), the number of fishing days left on time $t$ for sub fleet $s$ is (with $\Delta T=52 \Delta t$ or one year):

$$
\left\{\begin{array}{c}
n_{\text {days }, s}(t)=n_{\text {days }, s}^{0} n_{\text {vessel }}(t) \text { for } t=n \Delta T(n \in \mathbb{Z}) \\
n_{\text {days }, s}(t)=\max \left\{n_{\text {days }, s}(t-\Delta t)-Z_{s g} n_{\text {days }, s} n_{\text {vessel }, s} \Delta t, 0\right\} \\
\text { for } t=n \Delta t \neq m \Delta t(n, m \in \mathbb{Z}) .
\end{array}\right.
$$

Where $n_{\text {days }, s}^{0}$ is the initial number of fishing days for sub fleet $s, n_{\text {days }, s}$ is the number of days at sea in a week (in a $\Delta t$ ) for sub fleet $s, n_{\mathrm{vessel}, s}$ and is the number of vessels for sub fleet $s$ on time $t$.

In equation (1), the amount of total quota left for fishing ground $g$ is given by (with $\Delta T=52 \Delta t$ or one year):

$$
\left\{\begin{array}{c}
Q_{g}(t)=Q_{g}^{0} \quad \text { for } t=n \Delta t(n \in \mathbb{Z}) \\
Q_{g}(t)=\max \left\{Q_{g}(t-\Delta t)-c_{s g} n_{\mathrm{vessel}, s} Z_{s g} \Delta t, 0\right\} \\
\text { for } t=n \Delta t \neq m \Delta t(n, m \in \mathbb{Z}) .
\end{array}\right.
$$

Where $Q_{g}^{0}$ is the initial amount of quota for fishing ground $g$.

The fishing tactical decision rule (Eq. (1)) determines $G_{s}(t)$ which is the average gross operating profit for an average vessel for sub fleet $s$ on time $t$.

$$
G_{s}(t)=\frac{R_{s}(t)-O C_{s}(t)}{n_{\mathrm{vessel}, s(t)}}
$$

Where $R_{s}(t)$ is revenue for sub fleet $s$ on time $t$ and $O C_{s}(t)$ is operational cost for sub fleet $s$ on time $t$.

The revenue for a sub fleet $s$ on time $t$ is:

$$
R_{s}(t)=n_{\mathrm{vessel}, s}(t) P_{\text {fish }}(t) \sum_{g} c_{s g}(t) Z_{s g}(t) .
$$

In equation (4), the operational cost for sub fleet $s$ on time $t$ is:

$$
O C_{s}(t) \sum_{g}\left(V C_{s g}(t)+\operatorname{Tr} C_{s g}(t)\right) Z_{s g}(t) .
$$

Where $V C_{s g}(t)$ is the variable cost for sub fleet $s$ for fishing ground $g$ on time $t$ and is given. The travelling cost $S C_{s g}(t)$ is not given and can be calculated from:

$$
\operatorname{Tr} C_{s g}(t)=2 d_{g} U_{s} n_{\mathrm{vessel}, s}(t) P_{\text {fish }}(t) .
$$

Where $d_{g}$ is the distance to the fishing ground $g, U_{s}$ is the given fuel consumption per kilometer for an average vessel of sub fleet $s$ and $P_{\text {fuel }}$ is the fuel price for a litre fuel on time $t$.

Additionally, the fishing tactical decision rule influences the investment decision rule through influencing the financial power of a sub fleet. The financial power of a sub fleet $s$ on time $t$ is measured in savings of a sub fleet $s$ on time $t$.

$$
S_{s}(t)=S_{s}(t-\Delta t)+E_{s}(t)-l_{\text {fin }, s}(t) .
$$

Where $S_{s}(t)$ is the savings of a sub fleet $s$ on time $t, E_{s}$ is earnings for sub fleet $s, I_{\mathrm{fin}, s}(t)$ is the financial result of the investment decision for sub fleet $s$ on time $t$.

In equation (8), earnings for sub fleet $s$ on time $t$ are:

$$
E_{s}(t)=R_{s}(t)-\left(F C_{s}(t)+O C_{s}(t)+R_{\mathrm{debt}, s}(t)\right) .
$$

Where $F C_{s}(t)$ is fixed costs for sub fleet $s$ on time $t$ and $R_{\text {debt,s }}(t)$ is the relay of debt for sub fleet $s$ on time $t$ which is a fixed fraction of the total debts of sub fleet $s$ on time $t$.

In equation (8), $I_{\mathrm{fin}, s}(t)$ depends on the outcome of the investment decision on time $t$. The investment decision contains three options: (i) investment in a new vessel, (ii) demolition of a vessel, and (iii) neither. $I_{i, s}(t)$ is the boolean variable that takes the value one on time $t$ if for sub fleet $s$ : (i) the number of licences left is strictly positive, (ii) the sum of money from the savings and the possible bank loan does not exceed a threshold value, and (iii) the remaining debts are not exceeding a threshold value. $I_{i, s}(t)$ is zero for all other situations.

Let $n_{\text {lic }}(t)$ be the number of licences left for the total fleet on time $t, L_{s}(t)$ is the possible bank loan for sub fleet $s$ on time $t, D_{s}(t)$ is the amount of debts for sub fleet $s$ on time $t, \theta_{S, L}$ the threshold value for $S_{S}(t)+L_{s}(t)$ and $\theta_{D}$ the threshold value for $D_{s}(t)$.

$$
I_{i, s}(t)=\left(n_{\mathrm{lic}}(t)>0 \text { and } S_{s}(t)+L_{S}(t) \theta_{S, L} \text { and } D_{s}(t)<\theta_{D}\right.
$$

$I_{d, s}(t)$ is then the boolean variable that takes the value one on time $t$ if for sub fleet $s$ : (i) the sum of money from the savings and the possible bank loan is negative and (ii) the number of 
vessels is strictly positive. $I_{d, s}(t)$ is zero for all other situations.

$$
I_{d, s}(t)=\left(S_{s}(t) \leq 0 \text { and } n_{\mathrm{vessel}, s}(t)>0\right) .
$$

In equation (8), $I_{\text {fin, } s}(t)$ for sub fleet $s$ on time $t$ can now be written as:

$$
\left.I_{\text {fin }, s}(t)=\left(I_{i, s}(t) P_{\text {newves }, s}(t)\right)\right)-\left(I_{d, s}(t) P_{\text {demoves }, s}(t)\right) .
$$

Where $P_{\text {newves,s}}(t)$ is the price of a new vessel for sub fleet $s$ on time $t$ and $P_{\text {demoves, } s}$ is the money sub fleet $s$ gets from the demolition of a vessel which is a demolition price, theoretically speaking.

The number of vessels in sub fleet $s$ on time $t$ is then given by:

$$
n_{\mathrm{vessel}, s}(t)=n_{\mathrm{vessel}, s}(t-\Delta t)+I_{i, s}(t)+I_{d, s}(t) .
$$

The scenarios (Table 4) used to test the effect of restrictive policy instruments on the performance and dynamics of the Belgian fleet are based either on univariate or multivariate sensitivity simulations (Monte Carlo simulation). Each scenario has a time horizon of 18 years (936 weeks, from January 1, 1997 , till December 31,2014$)$ with a time step $(\Delta t)$ of a week. The first nine years show the fit between the simulated data and the historical data (reference mode). From 2005 on, the simulated data from the scenarios gives insights to the future behaviour of the fleet performance and dynamics till the year 2015.

To run the simulation model with its sensitivity simulations, data was collected from individual vessels on catch composition, effort allocation and financial situation for the years 1997 through 2005 (see Appendix). These data were compiled from two institutes. There is a very useful database called "Belsamp" hosted at the biological section of the Institute for Agriculture and Fisheries Research containing detailed data per individual vessel on catch composition and effort allocation. For financial data on an individual vessel level, the Belgian Sea Fishery Service of the Flemish government was addressed. They collect financial data for the Belgian sea fisheries fleet through a survey (on a voluntary annual basis, sample of approximately $50 \%$ of the fleet (i.e. approximately 65 vessels)). This study uses the data between the years 1997 and 2005 as variable input and to form a reference mode for the simulation model. From 2005 onward, all variable input data were kept constant at the 2005 level.

\section{Results}

In evaluating the explanatory power of a simulation model, the fit between the simulated data (baseline) and the historical data (reference mode) needs to be investigated. Since this study opts for a comprehensible model above a comprehensive model, the goodness-of-fit-statistics are quite poor (e.g. the R-square for average gross operating profit per vessel is 0.36). Nevertheless, Figure 4 illustrates that the graphs of the simulated data and the reference mode for average gross operating profit per vessel have the same basic behaviour, though the simulated data is systematically located below the historical data. This systematic fault is mainly because not all the

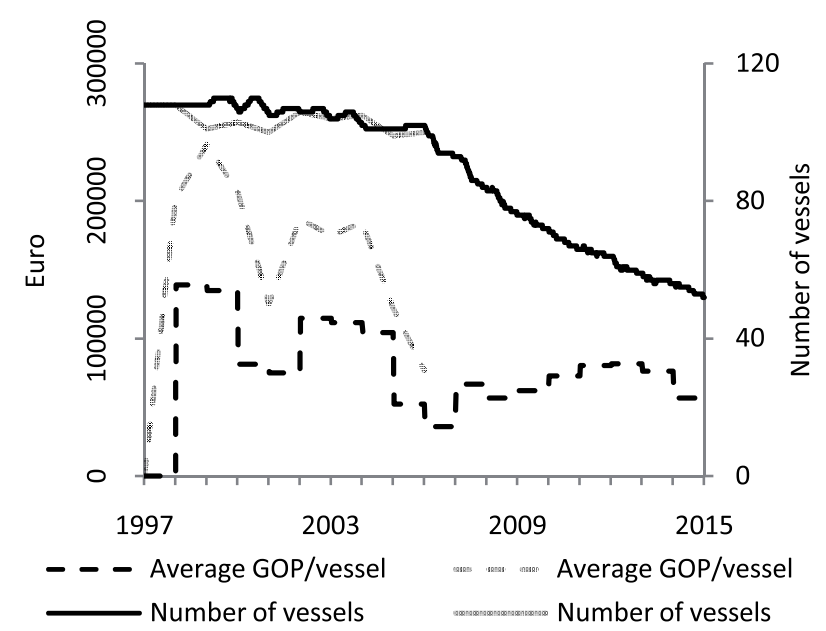

Fig. 4. The average gross operating profit per vessel (average $\mathrm{GOP} / \mathrm{vessel}$ ) and the number of vessels in the Belgian fleet between 1997-2014 (baseline $=$ simulation data $(=$ black $)$, reference mode $=$ historical data (= grey)).

Belgian fishing grounds with their total quota are included in the model. Additionally, average gross operating profit per vessel is a subtraction of revenues per vessel and operational costs per vessel, which are often both large figures in Belgian fisheries. Such calculation results in a small outcome easily subject to systematic under- or over-estimations.

Figure 4 also illustrates the fit between the simulated data and reference mode for "number of vessels in the fleet". Initially, the fit looks good but further inquiry into the individual dynamics of the sub fleets indicates a rapid conversion of the fleet which is only partly observed in reality (Fig. 5). This rapid conversion is caused by the systematically underestimation of average gross operating profit per vessel by the simulation model. As a result, non-profitable fisheries go bankrupt faster and "zero-profit fisheries" (Salz 2006) become non-profitable fisheries going bankrupt as well. Consequently, these bankrupt vessels exit the fleet, leaving fewer vessels with the residual amount of total quota. These remaining vessels will have a better opportunity for increasing their revenues and therefore increase their future investment potential. However, this explanation only contains an explanatory power when total quota are common pool resources and under the "ceteris paribus" clause. In conclusion, the simulation output is plausible taking into account the focus on the comprehensibility of the simulation model and the aim of the paper.

\subsection{Sensitivity simulation on the number of maximum fishing days}

The restrictive policy instrument of maximum fishing days influences fleet performance and dynamics by affecting the fishing tactics of fishermen (i.e. the boolean variable $Z_{s g}$ for $(s, g)$ in Eq. (1)). Two multivariate sensitivity analyses (each containing 1000 runs) were run to unveil the effect of changes of maximum $10 \%$ in maximum fishing days on fleet performance and dynamics (under the "ceteris paribus" clause). The four parameters under sensitivity simulation $\left(n_{\text {days }, s}\right.$ for every 
Table 4. Overview of the scenarios used to test the effect of restrictive policy instruments on fleet performance and dynamics. Type of variables: constant; Strength of the sensitivity simulations: 10\%; distribution function for the sensitivity simulations: random uniform.

\begin{tabular}{|c|c|c|c|c|c|c|c|}
\hline & $\begin{array}{c}\text { Type of } \\
\text { sensitivity } \\
\text { simulation }\end{array}$ & $\begin{array}{l}\text { Number of } \\
\text { runs in the } \\
\text { sensitivity } \\
\text { simulation }\end{array}$ & $\begin{array}{c}\text { Variable } \\
\text { under } \\
\text { sensitivity } \\
\text { simulation }\end{array}$ & Array of the variable & $\begin{array}{r}\text { Initial } \\
\text { value of } \\
\text { the } \\
\text { variable }\end{array}$ & $\begin{array}{r}\text { Minimum } \\
\text { value for the } \\
\text { sensitivity } \\
\text { simulation }\end{array}$ & $\begin{array}{r}\text { Maximum } \\
\text { value for the } \\
\text { sensitivity } \\
\text { simulation }\end{array}$ \\
\hline \multirow[t]{4}{*}{ Scenario 1} & Multivariate & 1000 & Maximum fishing days & Eurocutter & 200 & 180 & 200 \\
\hline & & & & Large beam trawler & 250 & 225 & 250 \\
\hline & & & & Set netter & 140 & 126 & 140 \\
\hline & & & & Shrimp trawler & 200 & 180 & 200 \\
\hline \multirow[t]{4}{*}{ Scenario 2} & Multivariate & 1000 & Maximum fishing days & Eurocutter & 200 & 200 & 220 \\
\hline & & & & Large beam trawler & 250 & 250 & 275 \\
\hline & & & & Set netter & 140 & 140 & 154 \\
\hline & & & & Shrimp trawler & 200 & 200 & 220 \\
\hline \multirow[t]{3}{*}{ Scenario 3} & Multivariate & 1000 & Total quota & IV bc & 14156674 & 12741007 & 14156674 \\
\hline & & & & VII de & 3555241 & 3199717 & 3555241 \\
\hline & & & & VII fg & 2350407 & 2115367 & 2350407 \\
\hline \multirow[t]{3}{*}{ Scenario 4} & Multivariate & 1000 & Total quota & IV bc & 14156674 & 14156674 & 15572342 \\
\hline & & & & VII de & 3555241 & 3555241 & 3910765 \\
\hline & & & & VII fg & 2350407 & 2350407 & 2585448 \\
\hline Scenario 5 & Univariate & 1000 & Licences & (None) & 110 & 99 & 110 \\
\hline Scenario 6 & Univariate & 1000 & Licences & (None) & 110 & 110 & 121 \\
\hline
\end{tabular}

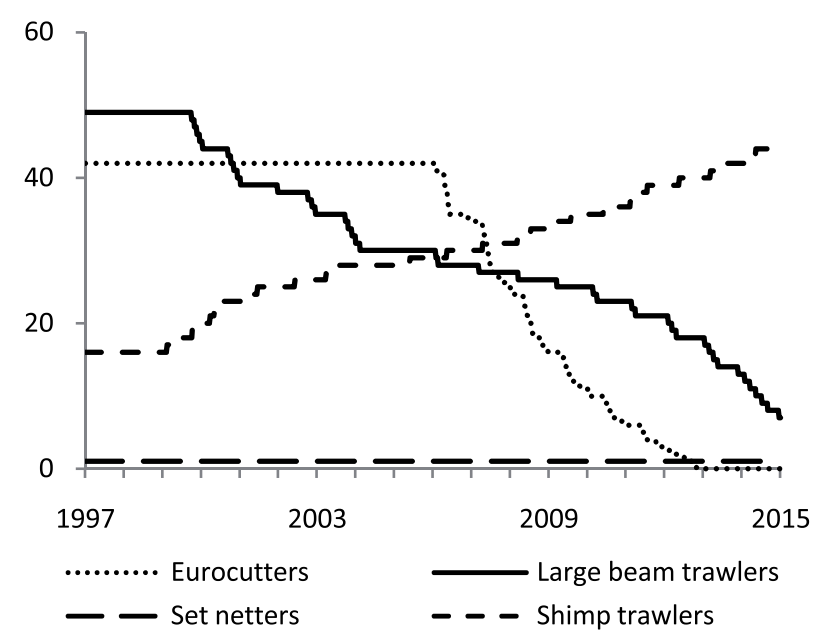

Fig. 5. Number of vessels per sub fleet between 1997-2014 (= simulated data).

$(s)$ ) were simultaneously and randomly varied between their maximum and minimum values (Table 4 ).

Figure 6 illustrates the impact of decreasing the number of maximum fishing days on average gross operating profit per vessel and total fleet size. When the mean value of average gross operating profit per vessel and total fleet size from the sensitivity simulation are compared with the values from the baseline, some small negative effect on future fleet performance and dynamics can be observed. By 2015, average gross operating profit per vessel will be $9.6 \%$ lower compared to the baseline.

In contrast, the outer bounds of the $95 \%$ confidence intervals also indicate the chance of a positive impact on average gross operating profit per vessel. This is counterintuitive and can be explained when vessels exit the fleet, since a decline in maximum fishing days caused them to go bankrupt.

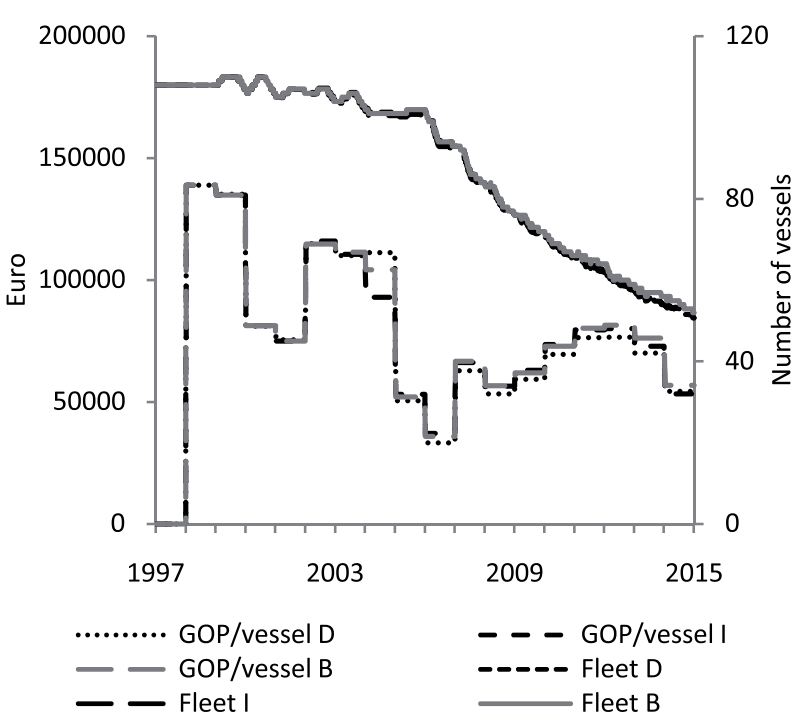

Fig. 6. The effect of sensitivity simulation implying a maximum $10 \%$ decrease and increase in maximum fishing days per sub fleet on the average gross operation profit per vessel and the number of vessels in the Belgian fleet between 1997 and 2015 (where: "D" = Decrease, "I" = Increase, and "B" = Baseline).

Consequently, a smaller fleet is left with the same amount of total quota. Even with less fishing days, some sub fleets can succeed in catching more fish because now they have the possibility to catch a larger proportion of the total quota. As a result of equation (5), more catch leads to more revenues and therefore increases average gross operating profit per vessel for these sub fleets (Eq. (4)). This increase in average gross operating profit per vessel can result in a general increase in average gross operating profit for a vessel of the total fleet. However, this explanation is only valid when total quota are common pool resources and given the "ceteris paribus" clause. 


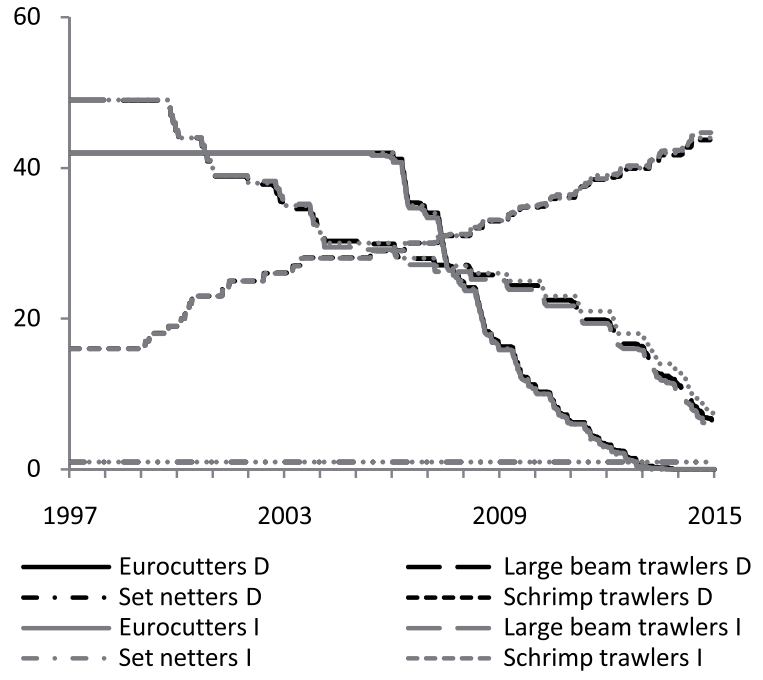

Fig. 7. The effect of sensitivity simulation implying a maximum $10 \%$ decrease and increase in maximum fishing days per sub fleet on the number of vessels per Belgian sub fleet between 1997 and 2015 (where: "D" = Decrease, "I" = Increase, and "......." = Baseline).

Figure 7 illustrates the impact a decrease in maximum fishing days has on sub fleet dynamics. Compared to the baseline, most sub fleets have no immediate dramatic changes in fleet size. Only large beam trawlers have a large $95 \%$ confidence interval. As a result, they are the sub fleet whose size is the most sensitive to changes in maximum fishing days.

If the number of maximum fishing days per sub fleet increases, both the average gross operating profit per vessel and total Belgian fleet size generated by the sensitivity simulation slightly decreases in the long term (approximately -5\%) (Fig. 6). Further inquiry on the sub fleet level indicates that on average no sub fleet significantly increases due to the additional maximum fishing days (Fig. 7). In contrast, the sub fleet of the large beam trawlers even decreases. This counterintuitive behaviour is caused mainly by the fishing tactical decision rule (Eq. (1)). The rule sends the sub fleets to the fishing ground with the highest catch per unit of effort, not taking into account the amount of fuel necessary to steam toward this "best" fishing ground. With the high fuel prices in the model (and in reality), this behaviour can lead to financial losses on trip level resulting in declining average gross operating profit per vessel. If sub fleets are given more fishing days, this decision rule sends fishermen to these further located fishing grounds more often. Consequently, these extra trips can result in financial losses on trip level leading to a decrease in average gross operating profit. Although this decision rule is artificial, many fishermen act in similar ways. Giving them extra fishing days will result in more time spent at sea without performing a decent cost-benefit analysis.

\subsection{Sensitivity simulation on the amount of total quota}

Total quota regulations restrict the amount of fish the fleet is allowed to land during a certain time frame. In Belgium, each fishing ground has its own total quota. Therefore,

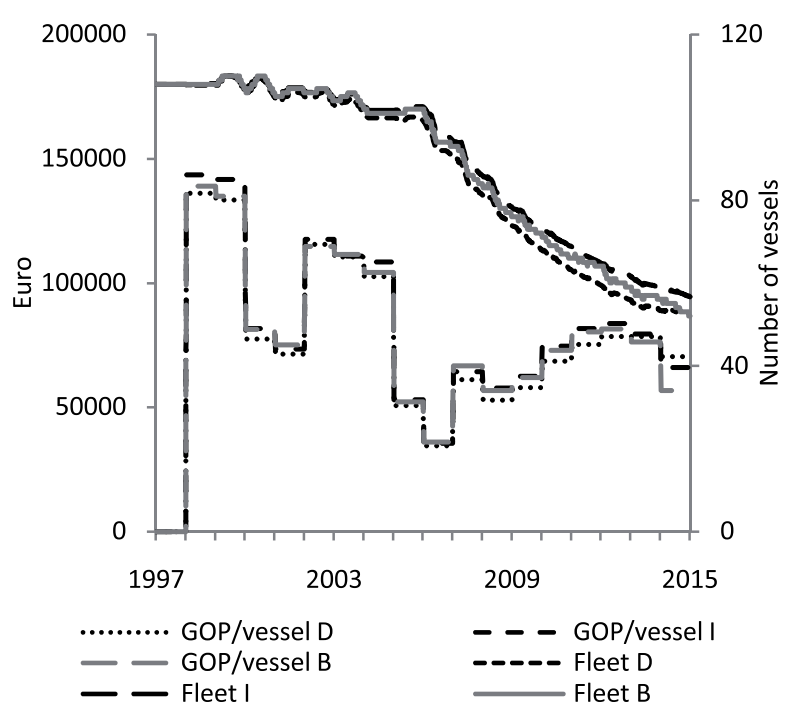

Fig. 8. The effect of sensitivity simulation implying a maximum $10 \%$ decrease and increase in total quota per fishing ground on the average gross operation profit per vessel and the number of vessels in the Belgian fleet between 1997 and 2015 (where: "D" = Decrease, "I" = Increase, and "B" = Baseline).

changing these amounts of total quota affects the fishing tactics of fishermen (Eq. (1)). Two similar multivariate sensitivity simulations as for maximum fishing days are performed to analyse the effect of changes of maximum $10 \%$ of the amount of total quota on fleet performance and dynamics. These sensitivity simulations have three parameters under sensitivity: $Q_{g}$ for every $(g)$ (Table 4).

When the amounts of total quota are decreased, the mean value of average gross operating profit per vessel from the sensitivity simulation is situated below the baseline until the end of 2012 (Fig. 8). This gap was at its maximum in 2007 at $9.2 \%$. From 2013 onward, this mean value started to exceed the baseline. In 2015, this gap reaches $24 \%$. The average value for the number of vessels in the fleet shows a similar behaviour. Consequently, decreasing the amounts of total quota on fishing grounds can result in a better performing fleet in the long run without further harming its size.

This outcome is not expected and therefore counterintuitive. This behaviour is caused mainly by two mechanisms. First, large beam trawlers leave the business a bit faster compared to the baseline (Fig. 9) resulting in a smaller fleet which is left earlier with the same amount of total quota leading to an increased average gross operating profit per vessel (as earlier explained). Second, if total quota on fishing grounds far off shore are lowered, these quota can be exploited with less trips, often resulting in financial losses. Subsequently, their negative impact on gross operating profit per vessel of the fleet will be more limited (as earlier explained).

The fleet dynamics on sub fleet level indicate on average a faster decline in the number of large beam trawlers due to a decrease in total quota (Fig. 9). In the long run, this decline is beneficial for the number of eurocutters, since both sub fleets compete for quota on the same fishing grounds. The other two sub fleets show no immediate major changes in fleet size compared to the baseline. 


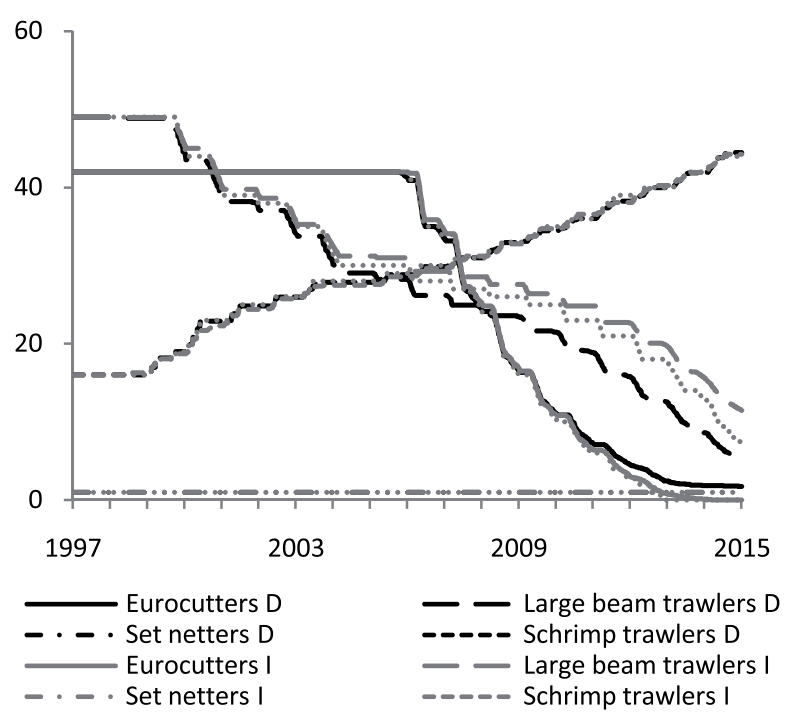

Fig. 9. The effect of sensitivity simulation implying a maximum $10 \%$ decrease and increase in total quota per fishing ground on the number of vessels per Belgian sub fleet between 1997 and 2015 (where: "D" = Decrease, "I" = Increase, and "......." = Baseline).

When the amount of total quota increases (maximum $10 \%$ ), the average gross operating profit per vessel almost certainly slightly increases (Fig. 8). This is translated into a slower decrease in total fleet size. In the long run, there is even room for a fleet recovery (indicated by the upper boundary of the $95 \%$ confidence interval). This possible fleet recovery is due to a slower decline in the number of large beam trawlers (also broad confidence intervals) combined with the increase in shrimp trawlers (Fig. 9).

\subsection{Sensitivity simulation on the number of licences}

This restrictive policy instrument limits the total fleet size by influencing (Eq. (10)) of the investment decision rule. The effect of changes of maximum $10 \%$ in the number of licenses on fleet performance and dynamics is tested by two univariate sensitivity analyses (1000 runs). The parameter under sensitivity is $n_{\text {lic }}$ (Table 4).

The effect of decreasing the number of licences on the average gross operating profit per vessel is small (on average $\pm 3 \%$ deviation compared to the baseline) with exception of 2014 (deviation of $+11.9 \%$ ) (Fig. 10). The same conclusions can be drawn for the total fleet size. However, the small change in total fleet size houses an interesting finding at the sub fleet level. The decline in the number of licences delays the growth of the shrimp trawler fleet (Fig. 11). More generally speaking, if a sub fleet is profitable, its fleet size can only grow as long as licences are available (Eq. (10)). As a result, the protective power of licences also blocks the growth of successful sub fleets.

Average gross operating profit per vessel, the total fleet size and the sub fleet sizes are not affected by an increase in the number of licences because it has no direct impact on fleet performance given the scope of our model. Consequently, increasing the number of licenses when the total fleet size is continuously decreasing has obviously no impact on future fleet performance and dynamics.

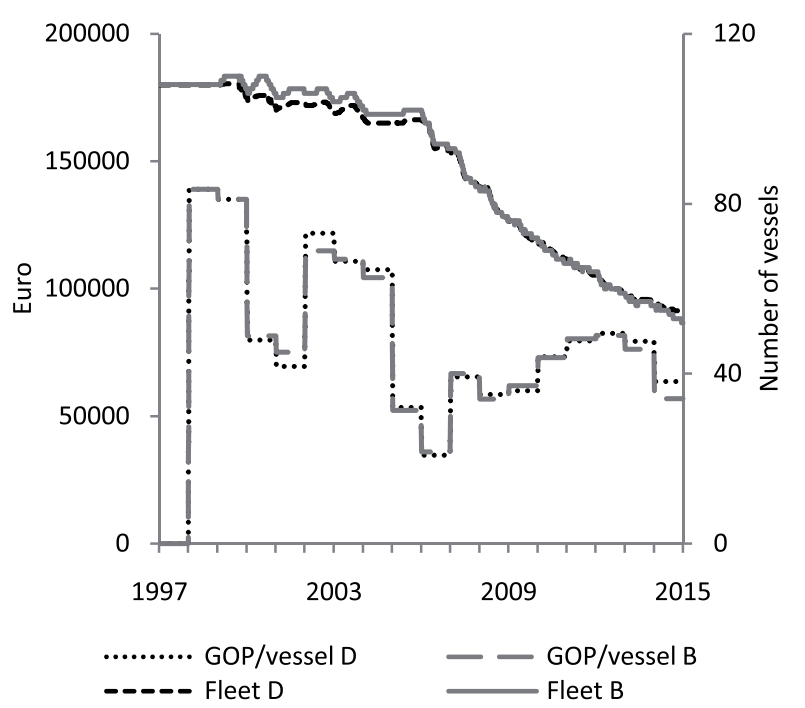

Fig. 10. The effect of a sensitivity simulation implying a maximum $10 \%$ decrease in licences on the average gross operation profit per vessel and the number of vessels in the Belgian fleet between 1997 and 2015 (where: "D" = Decrease, and "B" = Baseline).

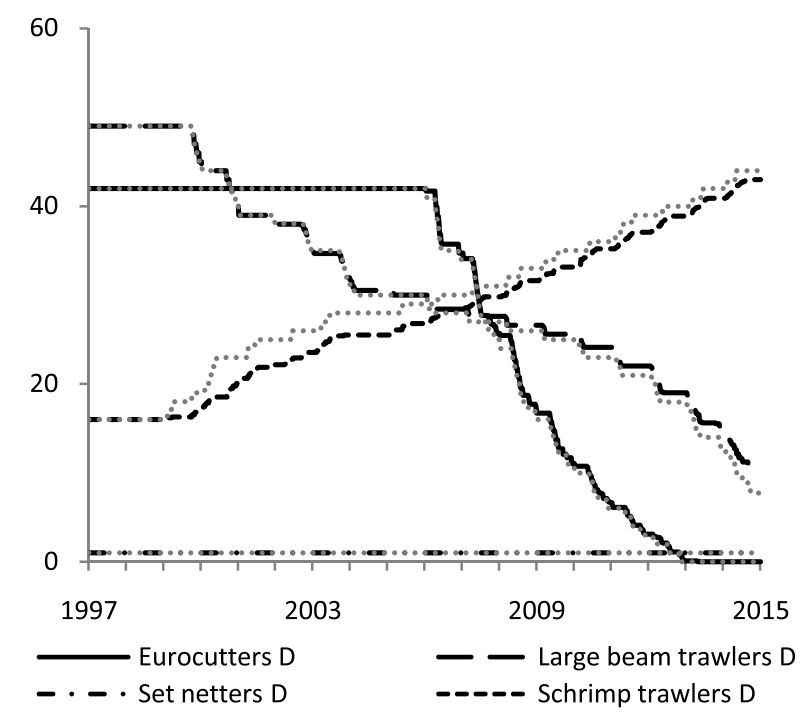

Fig. 11. The effect of a sensitivity simulation implying a maximum $10 \%$ decrease in licences on the number of vessels per Belgian sub fleets between 1997 and 2015 (where: "D" = Decrease, and "......." = Baseline).

\section{Discussion}

This study shows that the effect of restrictive policy instruments on fishing fleet dynamics is not uniform. A distinction needs to be made between restrictive policy instruments affecting the fishing tactical decisions and those affecting the investment decisions. For the Belgian case, changes in maximum fishing days and total quota result in larger changes in fleet performance and dynamics compared to changes in licences. Furthermore, changes in the first category have a direct impact on fleet performance, though not always as expected. Licences only affect fleet performance indirectly since they limit the entry of new vessels to the fleet on the one hand 
and they often block the growth of successful sub fleets on the other.

A constantly returning observation was counterintuitive behaviour of fleet performance and dynamics due to certain policy changes. This counterintuitive behaviour is partly caused by "misperception of feedback" (Sterman 1989; Diehl and Sterman 1995). "Misperception of feedback" is often observed in managing natural resources (Moxnes 1998ab) and occurs when a system is dynamically complex (Senge 1990). In Belgium, as in many other countries, the "system" of managing fisheries is dynamically complex because it consists of many interactions between reinforcing and balancing feedback loops. Consequently, changing the strength of restrictive policy instruments can result in a counterintuitive outcome.

Next, the results must be translated into practical suggestions for policy makers to improve fisheries management. Since this study is a basic study and further research on this topic is needed for the Belgian case, the practical suggestion will be general guidelines in the usage of restrictive policy instruments. Most importantly, policy makers need to be aware of misperceptions of feedback when changes are made in restrictive policy instruments. Therefore, further research will try to introduce our simulation model in the group of Belgian policy makers making them (more) aware of these counterintuitive effects. Second, the results show that altering only one type of restrictive policy instrument often will not result in the desired output, or will simply be inappropriate (e.g. increasing the number of maximum fishing days when total quota are already fully exploited). Therefore, policy makers need to find a balance in combining policy instruments. Finally, when increased fleet performance is the aim for future fisheries management, the authors' advice for the short term (and taking into account the scope of the model) is to convert the total fleet toward a smaller and more profitable fleet. This study proved that the restrictive policy instruments that affect the fishing tactics of fishermen are most suitable in meeting this objective. The authors prefer to decrease the maximum fishing days for every sub fleet by the same substantial percentage, resulting in highly unproductive large beam trawlers exiting the fleet, leaving more room for productive vessels to enhance profitability. If necessary, total quotas can be slightly increased to compensate for the loss in fishing days. The highly productive sub fleets will benefit from this policy. As a result, the fleet will be profitable, making future investment an option again.

This brings us to the discussion of the future value of restrictive policy instruments. Since fisheries management science has broadened its scope from a purely biological (Russell 1931; Graham 1935) over a bioeconomic (Gordon 1953, 1954; Scott 1955; Crutchfield 1956, 1959) to finally a political bioregunomics approach (Walters 1980; Anderson 1987), many studies have questioned the future value of restrictive policies (Barber 1988; Larkin 1996; Ruseski 1998; Boude et al. 2001; Polet et al. 2006). Anderson (1985: 409) even states that "the general conclusion of this literature is that traditional management techniques such as closed seasons, closed areas, gear restrictions, and total quotas are economically inefficient". The reason why restrictive policies are still commonly used lies in their power to preserve a "status quo" in fleet performance and dynamics. They serve the unwritten objective of preserving social peace. Boude et al. (2001) come to this same conclusion for the whole Common Fisheries Policy.

In Belgium, the key to social peace lies in preserving the (large) beam trawler fleet. For decades, this fishing method was highly profitable. However, with the recent and rapid changes in the fisheries environment (e.g. stock decline, changing catch per unit of effort and rising fuel prices), (restrictive) policies were put into place protecting these fisheries (e.g. more quota for larger vessels). Nevertheless, reality has shown that these policies cannot protect the beam trawler fleet any longer (e.g.: Stouten et al. (2007) indicates that the current and future rises in fuel prices result in beam trawlers going bankrupt even with these protective policies in place). Therefore, the time is right to break with the unwritten policy of preserving social peace. Policy makers should shift policies and stimulate a conversion towards a more profitable fleet. The solution might perhaps lie in a more diverse fleet consisting of different fishing methods and different vessel scales. The future value of restrictive policy instruments is to contribute to this conversion. However, traditions will need to be overcome and the restrictive policy instruments probably will need to be reengineered.

\section{Conclusion}

This paper evaluated the effect of changes in three restrictive policy instruments, respectively, maximum fishing days, total quota restrictions and licences on future fleet performance and dynamics. The used methodology of system dynamics and sensitivity simulation has proven to be very efficient in unveiling these effects.

The results indicated that changes in maximum fishing days and total quota resulted in higher fluctuations in fleet performance and dynamics compared to changes in licences. Additionally, changes in the first category had a direct impact on fleet performance, though not always as expected, whereas licences only affected fleet performance indirectly.

Although the effect of restrictive policy instruments on fishing fleet dynamics was not uniform, a constantly returning observation was counterintuitive behaviour partly caused by misperception of feedback. Being aware of this phenomenon is perhaps the most important recommendation for policy makers resulting from this paper. Also important was that the results proved that altering only one type of restrictive policy instruments at a time often fails to meet desired outcomes. Therefore, policy makers need to find a balance in combining policy instruments. In addition, this paper opened the discussion for rethinking the use of restrictive policy instruments in our rapidly changing, complex and uncertain fisheries environment. In Belgium, these policy instruments are currently aimed at "preserving the status quo and social peace". In the future, they should be used as a driving factor in "stimulating fleet dynamics". This opens a lot of further research opportunities.

Our further research will focus on two dimensions. First, research needs to be done to determine what kind of conversion is beneficial for the Belgian fleet and how to get there given certain policy instruments. Second, how can our simulation model change the thoughts of Belgian policy makers to fully back such a conversion? 
Appendix. Input data needed to run the baseline of the simulation model.

\begin{tabular}{|c|c|c|c|c|c|c|c|}
\hline Variable & Array & $\begin{array}{l}\text { Value type } \\
\text { in the } \\
\text { model }\end{array}$ & $\begin{array}{l}\text { Initial value } \\
\text { in the model } \\
\text { (mean value } \\
\text { year 1997) }\end{array}$ & $\begin{array}{c}\text { Unit of } \\
\text { measurement }\end{array}$ & $\begin{array}{c}\text { Real } \\
\text { or } \\
\text { proxy }\end{array}$ & $\begin{array}{c}\text { Data } \\
\text { source } \\
*\end{array}$ & $\begin{array}{c}\text { Descriptive statistics } \\
(1997-2005)\end{array}$ \\
\hline \multirow{4}{*}{$\begin{array}{l}\text { Maximum } \\
\text { fishing days }\end{array}$} & Eurocutter & Constant & 200 & day/vessel & Proxy & ILVO & \\
\hline & Large beam trawler & Constant & 250 & day/vessel & Proxy & ILVO & \\
\hline & Set netter & Constant & 140 & day/vessel & Proxy & ILVO & \\
\hline & Shrimp trawler & Constant & 200 & day/vessel & Proxy & ILVO & \\
\hline \multirow[t]{3}{*}{ Total quota } & IV bc & Constant & 14156674 & $\mathrm{~kg}$ & Real & SF & $\begin{array}{l}\text { Mean: } 14156674 \\
\text { Max: } 16952000 \text { - Min: } 11 \\
238500 \\
\text { St dev: } 1972497\end{array}$ \\
\hline & VII de & Constant & 3555241 & $\mathrm{~kg}$ & Real & $\mathrm{SF}$ & $\begin{array}{l}\text { Mean: } 3555241 \\
\text { Max: } 4219000-\text { Min: } 2860 \\
000 \\
\text { St dev: } 353225\end{array}$ \\
\hline & VII fg & Constant & 2350407 & $\mathrm{~kg}$ & Real & $\mathrm{SF}$ & $\begin{array}{l}\text { Mean: } 2350407 \\
\text { Max: } 3079500-\text { Min: } 1891 \\
000 \\
\text { St dev: } 423173\end{array}$ \\
\hline Licences & (None) & Constant & 110 & license & Proxy & ILVO & \\
\hline Fish price & (None) & Time series & 3.52 & euro/kg & Real & $\mathrm{SF}$ & $\begin{array}{l}\text { Mean: } 3.67 \\
\text { Max: } 4.07-\text { Min: } 3.39 \\
\text { St dev: } 022\end{array}$ \\
\hline Fuel price & (None) & Time series & 0.19 & euro/litre & Real & $\mathrm{SF}$ & $\begin{array}{l}\text { Mean: } 0.26 \\
\text { Max: } 0.43-\text { Min: } 0.16 \\
\text { St dev: } 0.08\end{array}$ \\
\hline \multirow{4}{*}{$\begin{array}{l}\text { Price for a } \\
\text { new vessel }\end{array}$} & Eurocutter & Constant & 2100000 & euro & Proxy & ILVO & \\
\hline & Large beam trawler & Constant & 5000000 & euro & Proxy & ILVO & \\
\hline & Set netter & Constant & 1000000 & euro & Proxy & ILVO & \\
\hline & Shrimp trawler & Constant & 2100000 & euro & Proxy & ILVO & \\
\hline \multirow{4}{*}{$\begin{array}{l}\text { Demolition } \\
\text { price } \\
\text { (subsidies) }\end{array}$} & Eurocutter & Constant & 500000 & euro & Proxy & ILVO & \\
\hline & Large beam trawler & Constant & 1000000 & euro & Proxy & ILVO & \\
\hline & Set netter & Constant & 300000 & euro & Proxy & ILVO & \\
\hline & Shrimp trawler & Constant & 500000 & euro & Proxy & ILVO & \\
\hline \multirow{3}{*}{$\begin{array}{l}\text { Distance to } \\
\text { fishing } \\
\text { ground }\end{array}$} & IV bc & Constant & 150 & $\mathrm{~km}$ & Proxy & ILVO & \\
\hline & VII de & Constant & 350 & $\mathrm{~km}$ & Proxy & ILVO & \\
\hline & VII fg & Constant & 700 & $\mathrm{~km}$ & Proxy & ILVO & \\
\hline \multirow[t]{4}{*}{$\begin{array}{l}\text { Number of } \\
\text { vessels }\end{array}$} & Eurocutter & Variable & 42 & vessel & Real & ILVO & $\begin{array}{l}\text { Mean: } 32.7 \\
\text { Max: } 42-\text { Min: } 29 \\
\text { St dev: } 4.1\end{array}$ \\
\hline & Large beam trawler & Variable & 49 & vessel & Real & ILVO & $\begin{array}{l}\text { Mean: } 52.8 \\
\text { Max: } 56-\text { Min: } 49 \\
\text { St dev: } 2.6\end{array}$ \\
\hline & Set netter & Variable & 1 & vessel & Real & ILVO & $\begin{array}{l}\text { Mean: } 2.6 \\
\text { Max: } 4-\text { Min: } 1 \\
\text { St dev: } 1.0\end{array}$ \\
\hline & Shrimp trawler & Variable & 16 & vessel & Real & ILVO & $\begin{array}{l}\text { Mean: } 14.9 \\
\text { Max: } 16 \text { - Min: } 14 \\
\text { St dev: } 0.8\end{array}$ \\
\hline \multirow[t]{4}{*}{$\begin{array}{l}\text { Variable } \\
\text { costs }\end{array}$} & Eurocutter & Time series & 7181 & euro/week at sea & Real & $\mathrm{SF}$ & Mean: 7983 \\
\hline & Large beam trawler & Time series & 16570 & euro/week at sea & Real & $\mathrm{SF}$ & $\begin{array}{l}\text { St dev: } 745 \\
\text { Mean: } 16644 \\
\text { Max: } 17270 \text { - Min: } 15550 \\
\text { St dev: } 597\end{array}$ \\
\hline & Set netter & Time series & 2779 & euro/week at sea & Real & $\mathrm{SF}$ & $\begin{array}{l}\text { Mean: } 4703 \\
\text { Max: } 8181-\text { Min: } 2779 \\
\text { St dev: } 1566\end{array}$ \\
\hline & Shrimp trawler & Time series & 2027 & euro/week at sea & Real & $\mathrm{SF}$ & $\begin{array}{l}\text { Mean: } 2904 \\
\text { Max: } 4357 \text {-Min: } 1674 \\
\text { St dev: } 944\end{array}$ \\
\hline \multirow[t]{2}{*}{ Fixed costs } & Eurocutter & Time series & 1049 & euro/week & Real & $\mathrm{SF}$ & $\begin{array}{l}\text { Mean: } 1101 \\
\text { Max: } 1222-\text { Min: } 895 \\
\text { St dev: } 102\end{array}$ \\
\hline & Large beam trawler & Time series & 2673 & euro/week & Real & $\mathrm{SF}$ & $\begin{array}{l}\text { Mean: } 2669 \\
\text { Max: } 2871-\text { Min: } 2529 \\
\text { St dev: } 108\end{array}$ \\
\hline
\end{tabular}


Appendix. Continued.

\begin{tabular}{|c|c|c|c|c|c|c|c|}
\hline Variable & Array & $\begin{array}{c}\text { Value type } \\
\text { in the } \\
\text { model }\end{array}$ & $\begin{array}{l}\text { Initial value } \\
\text { in the model } \\
\text { (mean value } \\
\text { year 1997) }\end{array}$ & $\begin{array}{c}\text { Unit of } \\
\text { measurement }\end{array}$ & $\begin{array}{c}\text { Real } \\
\text { or } \\
\text { proxy }\end{array}$ & $\begin{array}{c}\text { Data } \\
\text { source } \\
*\end{array}$ & $\begin{array}{c}\text { Descriptive statistics } \\
(1997-2005)\end{array}$ \\
\hline & Set netter & Time series & 299 & euro/week & Real & $\mathrm{SF}$ & $\begin{array}{l}\text { Mean: } 362 \\
\text { Max: } 536-\text { Min: } 299\end{array}$ \\
\hline & Shrimp trawler & Time series & 427 & euro/week & Real & $\mathrm{SF}$ & $\begin{array}{l}\text { St dev: } 96 \\
\text { Mean: } 588 \\
\text { Max: } 860-\text { Min: } 427 \\
\text { St dev: } 130\end{array}$ \\
\hline \multirow[t]{4}{*}{ Debts } & Eurocutter & Constant & 62190914 & euro & Proxy & ILVO & \\
\hline & Large beam trawler & Constant & 184830374 & euro & Proxy & ILVO & \\
\hline & Set netter & Constant & 4508181 & euro & Proxy & ILVO & \\
\hline & Shrimp trawler & Constant & 1371393 & euro & Proxy & ILVO & \\
\hline \multirow[t]{12}{*}{$\begin{array}{l}\text { Productivity } \\
\text { rate }\end{array}$} & $\begin{array}{l}\text { Eurocutter } \\
\text { IV bc }\end{array}$ & Time series & 5169 & $\mathrm{~kg} /$ week at sea & Real & ILVO & \multirow{12}{*}{$\begin{array}{l}\text { Mean: } 4482 \\
\text { Max: } 5221-\text { Min: } 3695 \\
\text { St dev: } 556 \\
\text { Mean: } 5043 \\
\text { Max: } 6105-\text { Min: } 3718 \\
\text { St dev: } 655 \\
\text { Mean: } 3313 \\
\text { Max: } 4277-\text { Min: } 2688 \\
\text { St dev: } 455 \\
\text { Mean: } 11132 \\
\text { Max: } 12820 \text {-Min: } 9300 \\
\text { St dev: } 1062 \\
\text { Mean: } 10320 \\
\text { Max: } 11223-\text { Min: } 9422 \\
\text { St dev: } 550 \\
\text { Mean: } 7171 \\
\text { Max: } 8469-\text { Min: } 6203 \\
\text { St dev: } 744 \\
\text { Mean: } 1809 \\
\text { Max: } 2295-\text { Min: } 922 \\
\text { St dev: } 438 \\
\text { Mean: } 2664 \\
\text { Max: } 5087-\text { Min: } 1575 \\
\text { St dev: } 1043 \\
\text { Mean: } 0 \\
\text { Max: } 0 \text {-Min: } 0 \\
\text { St dev: } 0 \\
\text { Mean: } 2836 \\
\text { Max: } 5263-\text { Min: } 1281 \\
\text { St dev: } 1352 \\
\text { Mean: } 1194 \\
\text { Max: } 2654-\text { Min: } 0 \\
\text { St dev: } 1023 \\
\text { Mean: } 505 \\
\text { Max: } 2925-\text { Min: } 0 \\
\text { St dev: } 1054\end{array}$} \\
\hline & $\begin{array}{l}\text { Eurocutter } \\
\text { VII de }\end{array}$ & Time series & 3718 & $\mathrm{~kg} /$ week at sea & Real & ILVO & \\
\hline & $\begin{array}{l}\text { Eurocutter } \\
\text { VII fg }\end{array}$ & Time series & 3168 & $\mathrm{~kg} /$ week at sea & Real & ILVO & \\
\hline & $\begin{array}{l}\text { Large beam trawler } \\
\text { IV bc }\end{array}$ & Time series & 12102 & $\mathrm{~kg} /$ week at sea & Real & ILVO & \\
\hline & $\begin{array}{l}\text { Large beam trawler } \\
\text { VII de }\end{array}$ & Time series & 9422 & $\mathrm{~kg} /$ week at sea & Real & ILVO & \\
\hline & $\begin{array}{l}\text { Large beam trawler } \\
\text { VII fg }\end{array}$ & Time series & 7767 & $\mathrm{~kg} /$ week at sea & Real & ILVO & \\
\hline & $\begin{array}{l}\text { Set netter } \\
\text { IV bc }\end{array}$ & Time series & 1959 & $\mathrm{~kg} /$ week at sea & Real & ILVO & \\
\hline & $\begin{array}{l}\text { Set netter } \\
\text { VII de }\end{array}$ & Time series & 1575 & $\mathrm{~kg} /$ week at sea & Real & ILVO & \\
\hline & $\begin{array}{l}\text { Set netter } \\
\text { VII fg }\end{array}$ & Time series & 0 & $\mathrm{~kg} /$ week at sea & Real & ILVO & \\
\hline & $\begin{array}{l}\text { Shrimp trawler } \\
\text { IV bc }\end{array}$ & Time series & 1850 & $\mathrm{~kg} /$ week at sea & Real & ILVO & \\
\hline & $\begin{array}{l}\text { Shrimp trawler } \\
\text { VII de }\end{array}$ & Time series & 922 & $\mathrm{~kg} /$ week at sea & Real & ILVO & \\
\hline & $\begin{array}{l}\text { Shrimp trawler } \\
\text { VII fg }\end{array}$ & Time series & 0 & $\mathrm{~kg} /$ week at sea & Real & ILVO & \\
\hline
\end{tabular}

\section{References}

Anderson L.G., 1987, Expansion of the fisheries management paradigm to include institutional structure and function. Trans. Am. Fish. Soc. 116, 396-404.

Anderson L.G., 1985, Potential economic benefits from gear restrictions and licence limitation in fisheries regulation. Land Econ. 61, 409-419.

Barber W.E., 1988, Maximum sustainable yield lives on. North Am. J. Fish. Manage. 8, 153-157.

Boude J., Boncoeur J., Bailly D., 2001, Regulating the access to fisheries: learning from European experiences. Mar. Policy 25, 313322 .
Charles A.T., 1998, Living with uncertainty in fisheries: analytical methods, management priorities and the Canadian ground fishery experience. Fish. Res. 37, 37-50.

Cochrane K.L., 1999, Complexity in fisheries and limitations in the increasing complexity of fisheries management. ICES J. Mar. Sci. 56, 917-926.

Crutchfield J.A., 1956, Common property resources and factor allocation. Can. J. Econ. Polit. Sci. 22, 292-300.

Crutchfield J., 1959, Biological and economic aspects of fishery management. Seattle, University of Washington Press.

Diehl E., Sterman J.D., 1995, Effects of feedback complexity on dynamic decision making. Organ. Behav. Hum. Decis. Process. 62, 198-215. 
Dudley R.G., 2003, A Basis for understanding fishery management complexities. In: Proc. International System Dynamics Conference, July 20-24, New York City.

Dudley R.G., 2006, Fisheries decision making and management failure: better answers require better questions. http://www.people. cornell.edu/pages/rgd6/PDF/fishlups.pdf.

Gordon H., 1953, An economic approach to the optimum utilisation of fishery resources. J. Fish. Res. Board Can. 10, 442-457.

Gordon H., 1954, The economic theory of the common property resource: the fishery. J. Polit. Econ. 62, 124-142.

Graham M., 1935, Modern theory of exploiting a fishery, and application to North Sea trawling. ICES J. Mar. Sci. 10, 264-274.

Healey M.C., Hennessey T., 1998, The paradox of fairness: The impact of escalating complexity on fishery management. Mar. Policy 22, 109-118.

Lane D.E., Stephenson R.L., 1999, Fisheries-management science: a framework for the implementation of fisheries-management systems. ICES J. Mar. Sci. 56, 1059-1066.

Larkin P.A., 1996, Concepts and issues in marine ecosystem management. Rev. Fish. Biol. Fish. 6, 139-164.

Mathiesen C., 2003, Analytical framework for studying fishers' behaviour and adaptation strategies. In: Proc. 8th Conference of the Circumpolar Arctic Social Sciences Ph.D. Network, August, 2003.

Moxnes E., 1998a, Not only the tragedy of the commons: misperceptions of bioeconomics. Manage. Sci. 44, 1234-1248.

Moxnes E., 1998b, Overexploitation of renewable resources: The role of misperceptions. J. Econ. Behav. Organ. 37, 107-127.

Moxnes E., 1999, Near-to-optimal harvesting strategies for a stochastic multicohort fishery. Report No. 56, Bergen, Centre for Fisheries Economics.
Moxnes E., 2003, Uncertain measurements of renewable resources: approximations, harvesting policies and value of accuracy. J. Environ. Econ. Manage. 45, 85-108.

Opaluch J., Bockstael N.E., 1984, Behavioral modeling and fisheries management. Mar. Resour. Econ. 1, 105-115.

Polet H., Depestele J., Stouten H., Vanderperren E., 2006, Moving from beam trawls towards multi-rig otter trawls - and further... In: Proc. Conference on energy efficiency in fisheries, 11-12 May, Brussels.

Ruseski G., 1998, International fish wars: the strategic roles for fleet licensing and effort subsidies. J. Environ. Econ. Manage. 36, 7088.

Russell E.S., 1931, Some theoretical considerations on the "overfishing" problem. ICES J. Mar. Sci. 6, 3-20.

Salz P., 2006, Economic performance of EU fishing fleets and consequences of fuel price increase. In: Proc. Conference on energy efficiency in fisheries, 11-12 May, Brussels.

Scott A., 1955, The fishery: the objectives of sole ownership. J. Polit. Econ. 63, 116-124.

Senge P., 1990, The fifth discipline: the art of practice of the learning organization. London, Century business.

Sterman J.D., 1989, Modeling managerial behavior: misperceptions of feedback in a dynamic decision making experiment. Manage. Sci. 35, 321-339.

Stouten, H., Van Craeynest, K., Heene, A., Gellynck, X., Polet, H., 2007, The effect of fuel price scenarios on Belgian fishing fleet dynamics. In: Proc. 2007 ICES Annual Science Conference, Sept 17-21, Marina Congress Center, Helsinki, Finland.

Walters C.J., 1980, Systems principles in fisheries management. In: Fisheries management Science, New York, Wiley. 